\title{
The modeling and optimization of hot rolling process of A36 structural steel by using response surface methodology
}

\author{
Avita Ayu Permanasari ${ }^{1, *}$, Poppy Puspitasari ${ }^{1}$, Moch. Agus Choiron $^{2}$, Andoko $^{1}$ and \\ Muhammad Taufiq Affandi ${ }^{1}$ \\ ${ }^{1}$ Department of Mechanical Engineering, State University of Malang, 65145 Malang, Indonesia \\ ${ }^{2}$ Department of Mechanical Engineering, Brawijaya University, 65145 Malang, Indonesia
}

\begin{abstract}
In hot conditions and with various parameters, it has been found several cracks and wear in the hot rolling process due to several factors including von mises stress and plastic strain which is affected by the size of the roller diameter and thickness of the specimen. Modeling and optimization using Response Surface Methodology (RSM) are chosen in this study to determine the optimum parameter design. The effect of roller diameter and thickness of specimens on equivalent stress von mises and plastic strains on the hot rolling process were studied using RSM. Central Composite Design (CCD) with two factors and three levels which are part of the RSM used to present mathematical models. Based on the results of RSM the optimum value obtained is on the roller diameter of $577.1389 \mathrm{~mm}$ and the thickness of the specimen $8.5786 \mathrm{~mm}$.
\end{abstract}

\section{Introduction}

Metal rolling is a process to reduce the thickness or cross-sectional area of a metal or work piece, bypassing the workpiece on a rotating roller. Hot rolling is a rolling process that is carried out when above the recrystallization temperature. A workpiece that passes through a rotating roller will experience surface stress and shear stress. Deformation of this process will cause the workpiece to increase in length, while the cross-sectional area or thickness will decrease. Hot rolling is also influenced by several parameters, such as stress, strain, stress rate, strain rate, reduction ratio, roller speed, a coefficient of friction, etc[1].

Furthermore, residual stresses can arise due to non-uniform deformation processes. Residual stresses usually occur on plates or sheets. The smaller the diameter of the roller the less the thickness reduction, this is due to the tendency to undergo plastic deformation on the surface of the plate or sheet. This condition causes residual compressive stresses on the surface and causes tensile stresses in or middle of the plate. Conversely, if the roller diameter

\footnotetext{
*Corresponding author: avita.ayu.ft@um.ac.id
} 
used is large and the reduction of thickness is also large, there will be a tendency for deformation in the center of the plate. This occurs because of high friction due to the larger contact area of the large roller diameter. Higher friction causes the residual stress distribution in large rollers to be opposite to the residual stress distribution in the small rollers. Deformation in the hot rolling process can result in defects, such as center burst, surface cracking, alligatoring, and edge cracking.

Finite Element Method (FEM) is one of the most widely used numerical methods in the world of engineering. FEM is widely applied to start from stress and deformation analysis in the fields of building structures, bridges, aviation, automotive, and there is fluid flow analysis, heat transfer, magnetic fields, and other non-structural problems. RSM is an optimization method to see the effect of the independent variable (x) on the response (y) by combining mathematical and statistical algorithms. From this method, it will obtain the optimum value of the variable $\mathrm{x}$.

In addition, [2](Shailendra Dwivesi, 2017) observed that percentage of reduction and roller diameter play is an important role in mechanical behavior. The result shows that higher reduction in slab thickness by small diameter may produce the damage. Then, [3](Bashishth Kumar Kushwaha, 2017) predicted equivalent stress and a plastic strain of hot rolling by varying the coefficient of friction and speed of the roller to see the quality of the product produced using FE 3D software. However, [4](Anikesh Tripathi, 2014) predicted the parameters of the hot rolling process by varying the coefficient of friction, roller diameter, and thickness of the plate. This study uses FE 2D software to see the effect of process parameters on equivalent von mises and plastic strains. [5] (Ali Heidari, 2011) optimizes the cold rolling process parameters with the chattering phenomenon using the Taguchi, ANN, and RSM methods.

The main purpose of this study is to see the effect of roller diameter and thickness of specimens on A36 Structural Steel during the hot rolling process with the help of FE 3D software. RSM was used in this study to determine the relationship of independent variables with responses. With this method, we will get the optimum value for each parameter of the rolling process systematically.

\section{Methodology of Research}

\subsection{Material}

The material chosen for the specimen is A36 structural steel is chosen because it is commonly used as standard construction material. Table 1 shows the Material properties of A36 structural steel.

Table 1. Physical properties A36 Structural Steel

\begin{tabular}{|c|c|c|c|c|}
\hline Density $(\mathrm{Kg} / \mathrm{m} 3)$ & $\begin{array}{c}\text { Young's } \\
\text { Modulus (GPa) }\end{array}$ & $\begin{array}{c}\text { Ultimate Tensile } \\
\text { Strength (MPa) }\end{array}$ & $\begin{array}{c}\text { Shear Modulus } \\
(\mathrm{GPa})\end{array}$ & Poisson Ratio \\
\hline 7800 & 200 & $400-550$ & 75 & 0.26 \\
\hline
\end{tabular}

\subsection{FEM}

ANSYS 18.1 is software used to model simulation with finite element method. A rolling model was developed to simulate the process of hot rolling of A36 structural steel bar and rollers with structural steel material using ANSYS 18.1 software. The geometry parameters 
of the hot rolling process varied are the diameter of the roller and the thickness of the specimen. The FEM geometry model and the rolling process are shown in Figure 1.

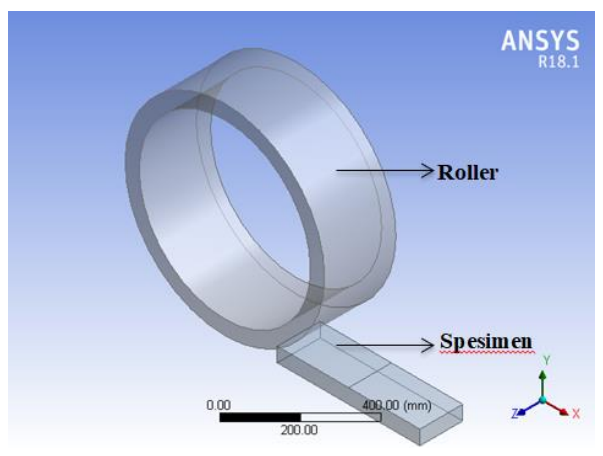

Fig. 1. FEM Model

\subsection{RSM Design}

Response Surface Methodology (RSM) is a combination of mathematical techniques and statistical techniques used to model and analyze a response that is influenced by several independent variables / factors $\mathrm{x}$ in order to optimize the response. The relationship between response $\mathrm{y}$ and $\mathrm{x}$ independent variables is:

$$
Y=f\left(X_{1}, X_{2}, \ldots, X_{k}\right)+\varepsilon
$$

Where:

$\mathrm{Y}=$ response variable

$\mathrm{Xi}=$ independent variables/factors $(\mathrm{i}=1,2,3, \ldots, \mathrm{k})$

$\varepsilon=$ error

The next step is to find the relationship between factor $\mathrm{x}$ and response $\mathrm{y}$ through the second order polynomial model and quadratic function, or better known as the second order model:

$$
\mathrm{Y}=\beta_{0}+\sum_{\mathrm{i}=1}^{\mathrm{k}} \beta_{\mathrm{i}} \mathrm{X}_{\mathrm{i}}+\sum_{\mathrm{i}=1}^{\mathrm{k}} \beta_{\mathrm{ii}} \mathrm{X}_{\mathrm{i}}^{2}+\sum \sum_{\mathrm{i}<\mathrm{j}} \beta_{\mathrm{ij}} \mathrm{X}_{\mathrm{i}} \mathrm{X}_{\mathrm{j}}+\varepsilon
$$

The second order experimental design used is a $3 \mathrm{k}$ factorial design (Three Level Factorial Design), which is suitable for optimization problems. Then from the second order model is determined the stationary point, surface response characteristics and the optimization model. The variables and levels in this experiment include:

1. Response variable (y), namely: Equivalent stress von mises and plastic strains

2. Independent variable/factor (x), namely: roller diameter and thickness of a specimen

3. The level used in each parameter, namely:

- High level $(+1)$ : Roller Diameter $(700 \mathrm{~mm})$ and Specimen Thickness $(250 \mathrm{~mm})$

- Middle level (0): Roller Diameter (500 mm) and Specimen Thickness (150 mm)

- Low level (-1): Roller Diameter (300 mm) and Specimen Thickness (50 mm)

The coding level and the level value of the variables that exist in the design of the second order experiment can be seen in Table 2 . 
Table 2. Code and Level Value from the order model II

\begin{tabular}{|c|c|c|}
\hline Variable & $\begin{array}{c}\text { Roller Diameter } \\
\text { (D) }\end{array}$ & $\begin{array}{c}\text { Specimen } \\
\text { Thickness (t) }\end{array}$ \\
\hline Level (-1,412) & $217 \mathrm{~mm}$ & $8,5 \mathrm{~mm}$ \\
\hline Low Level (-1) & $300 \mathrm{~mm}$ & $50 \mathrm{~mm}$ \\
\hline Middle Level (0) & $500 \mathrm{~mm}$ & $150 \mathrm{~mm}$ \\
\hline High Level (+1) & $700 \mathrm{~mm}$ & $250 \mathrm{~mm}$ \\
\hline Level (+1,412) & $782 \mathrm{~mm}$ & 291 \\
\hline
\end{tabular}

\section{Result and Discussion}

Table 2 shows the experimental design using central composite design (CCD) on the RSM method with 2 factors and 3 levels produces 13 design designs that will be simulated using Ansys to determine the value of the response variable (Equivalent von mises stress voltage and plastic strain).

Table 3. Results Analysis using RSM

\begin{tabular}{|c|c|c|c|c|}
\hline $\begin{array}{c}\text { Std } \\
\text { Order }\end{array}$ & $\begin{array}{c}\text { Roller Diameter } \\
(\mathrm{mm})\end{array}$ & $\begin{array}{c}\text { Specimen } \\
\text { Thickness }(\mathrm{mm})\end{array}$ & $\begin{array}{c}\text { Equivalent Von Mises } \\
\text { Stress (Mpa) }\end{array}$ & $\begin{array}{c}\text { Plastic Strain } \\
(\mathrm{mm})\end{array}$ \\
\hline 1 & 500 & 150 & 476,53 & 0,0040 \\
\hline 2 & 500 & 150 & 476,53 & 0,0040 \\
\hline 3 & 700 & 250 & 440,40 & 0,0040 \\
\hline 4 & 300 & 50 & 450,72 & 0,0034 \\
\hline 5 & 500 & 150 & 476,53 & 0,0040 \\
\hline 6 & 500 & 150 & 476,53 & 0,0040 \\
\hline 7 & 782,843 & 150 & 512,00 & 0,0034 \\
\hline 8 & 700 & 50 & 418,23 & 0,0015 \\
\hline 9 & 500 & 150 & 476,53 & 0,0040 \\
\hline 10 & 300 & 250 & 545,74 & 0,0047 \\
\hline 11 & 500 & 291,421 & 659,58 & 0,0041 \\
\hline 12 & 217,157 & 150 & 1005,70 & 0,0045 \\
\hline 13 & 500 & 8,579 & 289,15 & 0,0014 \\
\hline
\end{tabular}

\subsection{Second-order model for Equivalent Von Mises Stress and Plastic Strain}

Equation 3 and equation 4 show the second-order model of mathematical equations analyzed by the RSM method for roller diameter, specimen thickness, Equivalent von mises stress and plastic strain.

Equivalent von mises stress $=327,1-0,481 \mathrm{D}+1,088 \mathrm{t}+0,000040 \mathrm{D}^{2}$ $0,004239 \mathrm{t}^{2}+0,001583 \mathrm{D} * \mathrm{t}$

Where $\mathrm{D}$ is the roller diameter $(\mathrm{mm})$ and $t$ is the thickness of the specimen $(\mathrm{mm})$. The correlation coefficients resulting from equation 3 are R-sq $=0.9721$ and R-sq (adj) = 
0.9523. This shows that the second-order model of mathematical equations for equivalent stress von mises can explain the relationship of variable $\mathrm{x}$ and response $\mathrm{y}$ to $97.21 \%$.

Plastic strain $=0.003539-0.000005 \mathrm{D}+0.000020 \mathrm{t}-0.000000 \mathrm{D}^{2}-$

$0.000000 \mathrm{t}^{2}+0.000000 \mathrm{D} * \mathrm{t}$

The correlation coefficients generated from equation 4 are R-sq $=0.9887$ and R-sq (adj) $=0.9807$. This shows that the second-order model of mathematical equations for plastic strains can explain the relationship of variable $\mathrm{x}$ and response $\mathrm{y}$ to $98.87 \%$

\subsection{Analysis of Variant (Anova)}

Anova is a statistical method used to determine the significance of the model. The results of Anova are shown in Table 3 and Table 4 . This analysis uses 95\% confidence level and $5 \%$ error tolerance. Therefore, the smaller the $\mathrm{P}$ value, the more significant the effect of the $\mathrm{x}$-factor on the response $\mathrm{y}$.

Table 4. Anova results from Equivalent Stress Von mises

\begin{tabular}{|lccccc|}
\hline Source & DF & Adj SS & Adj MS & F-Value & P-Value \\
\hline Model & 5 & 59777,4 & 11955,5 & 48,87 & 0,000 \\
Linear & 2 & 42910,2 & 21455,1 & 87,69 & 0,000 \\
Roller Diameter & 1 & 13304,2 & 13304,2 & 54,38 & 0,000 \\
Specimen Thickness & 1 & 29606 & 29606 & 121,01 & 0,000 \\
Square & 2 & 12857,2 & 6428,6 & 26,28 & 0,001 \\
Roller Diameter * Roller Diameter & 1 & 17,7 & 17,7 & 0,07 & 0,796 \\
Specimen Thickness * Specimen Thickness & 1 & 12497,9 & 12497,9 & 51,08 & 0,000 \\
2-Way Interaction & 1 & 4010,1 & 4010,1 & 16,39 & 0,005 \\
Roller Diameter * Specimen Thickness & 1 & 4010,1 & 4010,1 & 16,39 & 0,005 \\
Error & 7 & 1712,6 & 244,7 & & \\
Total & 12 & 61490 & & & \\
\hline
\end{tabular}

Table 5. Anova results from plastic strain

\begin{tabular}{|lccccc|}
\hline Source & DF & Adj SS & Adj MS & F-Value & P-Value \\
\hline Model & 5 & 0,000012 & 0,000002 & 122,94 & 0,000 \\
Linear & 2 & 0,000009 & 0,000005 & 233,04 & 0,000 \\
Roller Diameter & 1 & 0,000002 & 0,000002 & 106,88 & 0,000 \\
Specimen Thickness & 1 & 0,000007 & 0,000007 & 359,21 & 0,000 \\
Square & 2 & 0,000003 & 0,000001 & 65,4 & 0,000 \\
Roller Diameter * Roller Diameter & 1 & 0,000000 & 0,000000 & 0,05 & 0,823 \\
Specimen Thickness *Specimen Thickness & 1 & 0,000003 & 0,000003 & 129,22 & 0,000 \\
2-Way Interaction & 1 & 0,000000 & 0,000000 & 17,82 & 0,004 \\
$\quad$ Roller Diameter *Specimen Thickness & 1 & 0,000000 & 0,000000 & 17,82 & 0,004 \\
Error & 7 & 0,000000 & 0,000000 & & \\
Total & 12 & 0,000013 & & & \\
\hline
\end{tabular}


Table 3 shows the $\mathrm{P}$ value of the model is 0,000 , this shows that the model for equivalent stress von mises has a significant effect. The parameter that most influences Equivalent von mises stress is the thickness of the specimen with the value F of 121.01 and the $\mathrm{P}$ value of 0.000 . Table 4 also shows if the model has a significant effect on a plastic strain. The parameter that most influences the plastic strain is the thickness of the specimen with an $F$ value of 359.21 and a $P$ value of 0.000 . $P$ value less than 0.05 indicates that the parameter has a significant effect on the response

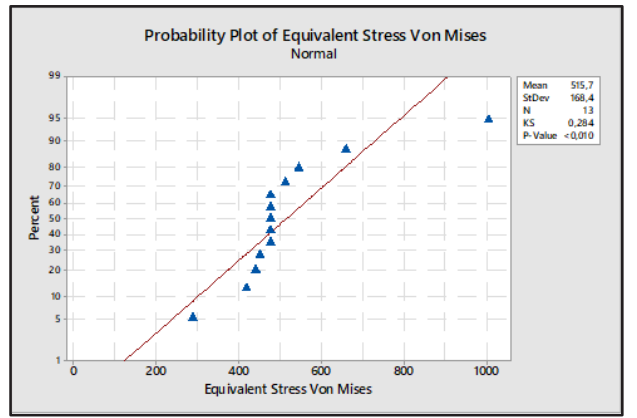

(a)

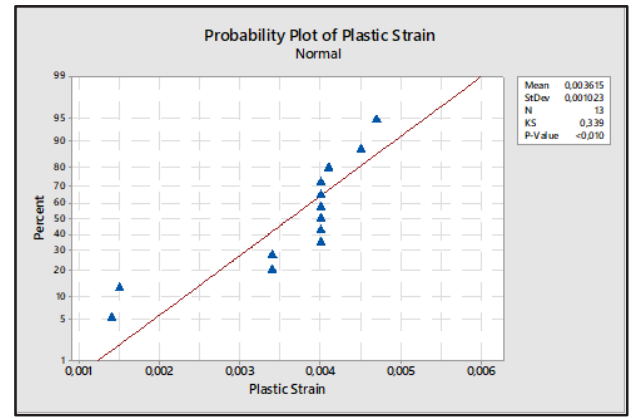

(b)

Fig. 2. Normal Probability Plot on (a) Equivalent Von mises Stress and (b) Plastic Strain

Normal probability plot for equivalent von mises stress and plastic strain is shown in Figure 2. Kolmogorov-Smirnov (KS) value on normal probability plot equivalent stress von mises is 0.284 , while the KS value for a plastic strain is 0.339 . The value of KS table obtained for equivalent stress von mises and plastic strains is 0.361 . If $\mathrm{KS}$ counts $<\mathrm{KS}$ table, then the residual normality test has been normally distributed.

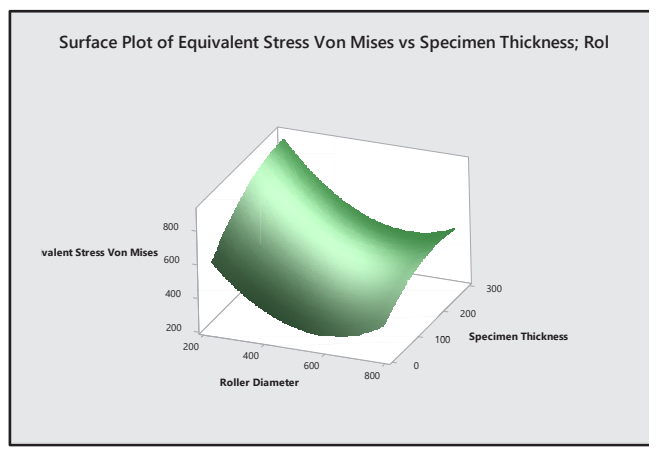

(a)

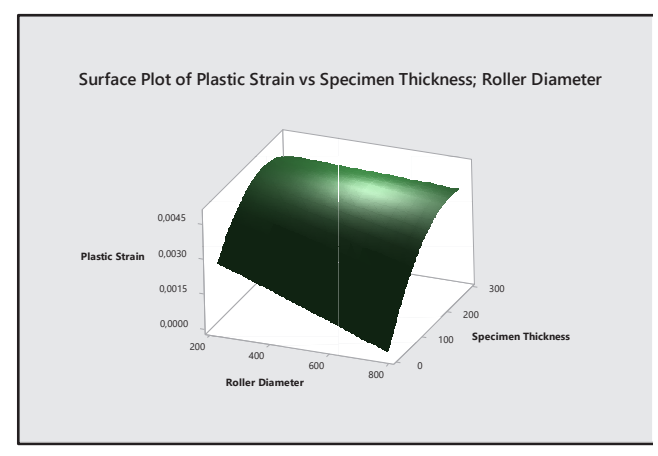

(b)

Fig. 3. Response Surface Plots (a) Equivalent Von mises Stress vs. specimen thickness of roller diameter and specimen thickness (b) Plastic strain vs. specimen thickness of roller diameter and specimen thickness

Figure 3 shows the plot of the surface of the Equivalent von mises stress response and the plastic strain on the roller diameter and thickness of the specimen. From this graph, there is an interaction between specimen thickness and roller diameters with Equivalent von mises stress and plastic strain. 


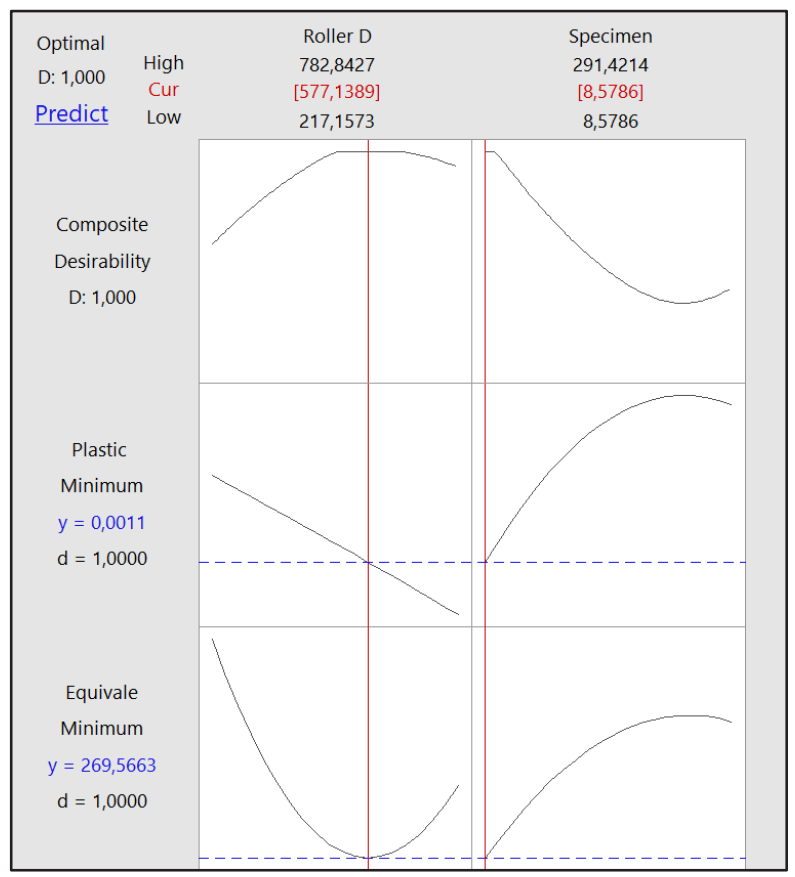

Fig. 4. Response Surface Plots (a) Equivalent von mises stress vs. specimen thickness of roller diameter and specimen thickness (b) Plastic strain vs. specimen thickness of roller diameter and specimen thickness

From Figure 4 it can be concluded that the optimum parameter design is a roller diameter of $577.1389 \mathrm{~mm}$ and a specimen thickness of $8.5786 \mathrm{~mm}$. From the optimum parameter design, minimum equivalent von mises stress value is $269,5663 \mathrm{MPa}$ and minimum plastic strain is $0,0011 \mathrm{~mm}$.

\section{Conclusion}

- The most influential parameters for equivalent von mises stress are specimen thickness with a contribution percentage of $48.15 \%$, followed by roller diameter with a contribution percentage of $21.63 \%$. For plastic strains, the most influential parameter is specimen thickness with a contribution percentage of $53.85 \%$ followed by roller diameter with a contribution percentage of $15.38 \%$.

- The second-order model mathematical equation developed for equivalent stress error estimates of von mises and plastic strains with correlation coefficients is 0.9721 and 0.9887 .

- Response surface plot shows that the optimum parameter design is roller diameter and specimen thickness is $577,1389 \mathrm{~mm}$ and $8,5786 \mathrm{~mm}$.

- From the optimum parameter design, the minimum equivalent stress value of von mises is $269,5663 \mathrm{MPa}$ and the plastic strain is $0.0011 \mathrm{~mm}$.

\section{References}

1. L. Yang, J. Ji, J. Hu, and A. Romagos, Mechanika, 17, 474-479 (2011)

2. S. Dwivedi, R. S. Rana, A. Rana, S. Rajpurohit, and R. Purohit, Mater. Today Proc 4, 
2360-2372 (2017)

3. B. K. Kushwaha and B. Moharana, Int. Res. J. Eng. Technol, 4 (3) 399-406 (2017)

4. A. Tripathi and A. Medhavi, Int. J. Sci. Res. Publ., 4 (1), 2250-3153 (2014)

5. A. Heidari and M. R. Forouzan, J. Adv. Res., 4, 27-34 (2013) 